\title{
Analysis of Nutrition Education in Osteopathic Medical Schools
}

\author{
Kathaleen Briggs Early, ${ }^{1}$ Kelly M. Adams, ${ }^{2}$ and Martin Kohlmeier ${ }^{2,3}$ \\ ${ }^{1}$ College of Osteopathic Medicine, Pacific Northwest University of Health Sciences, 200 University Pkwy, Yakima, WA 98901, USA \\ ${ }^{2}$ Department of Nutrition, School of Medicine and Gillings School of Global Public Health, \\ University of North Carolina at Chapel Hill, 800 Eastowne Drive, Suite 100, Chapel Hill, NC 27514, USA \\ ${ }^{3}$ UNC Nutrition Research Institute, 500 Laureate Way, Kannapolis, NC 28081, USA
}

Correspondence should be addressed to Martin Kohlmeier; mkohlmeier@unc.edu

Received 4 December 2014; Accepted 4 March 2015

Academic Editor: Lubna Baig

Copyright (c) 2015 Kathaleen Briggs Early et al. This is an open access article distributed under the Creative Commons Attribution License, which permits unrestricted use, distribution, and reproduction in any medium, provided the original work is properly cited.

\begin{abstract}
Purpose. Describe nutrition education at US colleges of osteopathic medicine; determine if it meets recommended levels. Method. We surveyed 30 US colleges of osteopathic medicine (US COM) with a four-year curriculum about the amount and form of required nutrition education during the 2012/13 academic year. The online survey asked about hours of required nutrition across all 4 years and also in what types of courses this instruction occurred. We performed descriptive statistics to analyze the data. Results. Twentysix institutions ( $87 \%$ response rate) completed the survey. Most responding US COM $(22 / 26,85 \%)$ do not meet the recommended minimum 25 hours of nutrition education; $8(31 \%)$ provide less than half as much. Required nutrition instruction is largely confined to preclinical courses, with an average of 15.7 hours. Only 7 of the 26 responding schools report teaching clinical nutrition practice, providing on average 4.1 hours. Conclusions. Most US COM are inadequately preparing osteopathic physicians for the challenges they will face in practice addressing the nutritional concerns of their patients. Doctors of osteopathy cannot be expected to properly treat patients or guide the prevention of cardiovascular disease, obesity, cancer, diabetes, and metabolic syndrome if they are not trained to identify and modify the contributing lifestyle factors.
\end{abstract}

\section{Introduction}

Seven of the top 10 causes of death in the US are chronic diseases [1]. Most of those (heart disease, cancer, stroke, and diabetes) have a strong nutrition component as a contributing factor, with risk increasing as BMI or waist circumference increases. Therefore, a large amount of the observed premature morbidity and mortality in the US is due to lifestyle habits related to nutrition and exercise habits [2]. Nutrition and lifestyle treatment strategies are integral to the care of patients with obesity, cardiovascular disease, diabetes, and cancer, as well as a multitude of other conditions, including anemia, malnutrition, gastrointestinal disease, and kidney disease. Physicians, especially primary care providers, play a critical role in overseeing the nutrition care and related concerns of their patients, by assessing nutrition risks, providing lifestyle counseling, and referring to other healthcare providers, such as registered dietitian nutritionists, who can aid the patient in achieving dietary and other lifestyle goals.
Moreover, nutrition continues to be a leading topic of fraud and deception for consumers; everything from weight loss to cancer therapies is susceptible to nutrition-related misinformation [3]. It is critically important that physicians understand how to prevent and treat nutrition-related conditions by separating high quality nutrition evidence from quackery to complement patient care needs and help reduce the high rates of lifestyle-related morbidity and mortality. Primary care practitioners thus face a number of barriers to providing nutrition care to their patients who could benefit from it [4]. Proper nutrition care improves patient outcomes and reduces costs [5]; without evidence-based nutrition education for physicians professional in training, there is no guarantee that every practitioner will obtain the essential competencies $[6,7]$.

Despite the importance of nutrition to health, nutrition education at US medical schools remains a very part of medical school curricula, and time spent covering nutrition lags far behind most other science topics. Most medical students 
unfortunately receive little training on how to make sense of applied nutrition topics during their medical training. The most commonly cited reason for these deficiencies is the already-packed undergraduate medical school curricula [8]. Calls for changes to this approach have been published many times over $[2,8-10]$, and in spite of nutrition being historically inseparable from medicine [11], it continues to receive little attention throughout the traditional four years of medical school. In fact, most US and European allopathic medical schools are failing to provide even the minimum of the 25 hours of nutrition instruction during a 4-year undergraduate medical program as recommended by the National Academy of Sciences and reported elsewhere in this supplement $[10,12]$.

Osteopathic medical training, founded in the US over 130 years ago, emphasizes patient-centered whole-person care. Osteopaths account for almost a quarter of all US medical school graduates, and more than $60 \%$ of osteopathy graduates become primary care providers [13]. Osteopathic physicians have full practice privileges in more than 65 countries around the world [14]. Osteopathy training in the US is similar to allopathic medical training in many ways. Both doctors of osteopathy (DOs) and allopathic physicians (MDs) need to have a four-year degree prior to entering medical school; both complete four years of medical school with a curriculum that primarily teaches basic sciences during the early months or years, while clinical training in the major medical specialties (family medicine, internal medicine, pediatrics, surgery, etc.) occurs in rotations (i.e., clerkships) throughout the latter years; both are required to pass state medical licensing exams if they want to practice medicine; both may prescribe medications and perform medical/surgical procedures after they passed licensing exams; and both work in a variety of health care settings from hospitals to long-term care facilities to private practices. During their clinical clerkships, osteopathic medical students are more likely than allopathic medical students to have required rotations in community settings such as rural clinics, rather than academic or tertiary care medical teaching centers. More osteopathic graduates pursue primary care practice specialties [15-17]. The biggest difference between these two medical degrees is that DO students receive training in manipulative medicine, typically throughout their first two years during osteopathic principles and practice (OPP), osteopathic manual medicine (OMM), or osteopathic manipulative treatment (OMT). Manipulative medicine involves a hands-on approach to diagnosis and treatment of patients in a primary or adjunctive way [18]. The tenets of osteopathic medicine recognize that the human body is capable of self-healing, self-regulation, and health maintenance [19]. Thus, nutrition education fits nicely within the osteopathic philosophy and practice framework.

For decades, many osteopathic medical schools have been attempting curriculum transformation or reformation, without any substantial changes overall [20-22]. Changes at some osteopathic schools have lagged behind those of allopathic medicine, despite the recognition that change is needed [23]. Many schools undertake curriculum reform in an effort to maximize real-world relevance and early clinical experiences, while reducing the isolated nature of basic versus clinical science courses. Nutrition is frequently taught in this environment under the auspices of biochemistry or physiology courses [24] although nutrition as an applied science overlaps with topics in biochemical, physiological, behavioral, clinical, and psychosocial courses.

The Nutrition in Medicine (NIM) Program, fully described elsewhere [25], is a web-based nutrition curriculum administered through the University of North Carolina at Chapel Hill's Department of Nutrition. The evidence-based, free online modules for medical students, residents, and physicians include learning objectives, visually appealing graphics, short video-vignettes, and quizzes. Currently more than 120 US medical schools and colleges of osteopathic medicine take advantage of at least one of these online modules. The NIM team has conducted and published four nutrition education surveys at four-year intervals since 2000 $[10,24,26]$. The NIM team collected data from osteopathic schools as part of these surveys; however, this is the first published report of any of the data from osteopathic schools, and, to the best of our knowledge, the first published analysis of nutrition education at US osteopathic medical schools.

The purpose of this study was to collect survey data on the required nutrition education at US colleges of osteopathic medicine during the academic year 2012/13 and gauge how well these schools met the recommendation of the National Research Council to include a minimum 25 hours of nutrition education in the curriculum [27].

\section{Methods}

Schools and colleges accredited by the Commission on Osteopathic College Accreditation (COCA) that had graduated a class of students by the summer of 2013 were surveyed by emailing nutrition educators and curriculum administrators. A hyperlink for easy survey access was included in the email. If schools did not respond to the initial email request, the NIM team made follow-up phone calls and emails. At the time of our survey origin, 28 schools were accredited by COCA. We also included two campuses that were in vastly different geographic locations (different states) from their parent school since their nutrition offerings were not necessarily representative of the parent institution. Therefore, a total of 30 campuses were asked to respond to the survey.

Except for the most recent addition of questions directly assessing obesity-related teaching, the NIM survey has remained the same since 2000. The survey contained 17 questions and a general comments section. For most answers, respondents were able to enter free text, to allow us to capture descriptions of unique and sometimes complex curricula. The first two questions asked about the size of the medical school and whether nutrition instruction was required, optional, or not offered. Questions 3-4 asked respondents to estimate the total number of required nutrition contact hours, specifying in which years the instruction was provided (1st/2nd years or $3 \mathrm{rd} / 4$ th years combined), and to indicate the type of course in which the nutrition content was taught (nutrition, physiology/pathophysiology, biochemistry, integrated, etc.). Questions 5-6 inquired about the use of the NIM curriculum at that institution, and questions 7-9 asked about 
TABLE 1: Nutrition instruction hours in various contexts at US colleges of osteopathic medicine that required nutrition education during the 2012/2013 academic year*.

\begin{tabular}{|c|c|c|c|c|c|}
\hline Course/context & Nutrition & Integrated & Biochemistry & Physiology & Clinical practice \\
\hline Number of schools & 4 & 16 & 12 & 6 & 7 \\
\hline $\begin{array}{l}\text { Number of hours of nutrition instruction in this } \\
\text { context, average (SD) }\end{array}$ & $14.0(8.8)$ & $16.3(12.3)$ & $6.9(5.6)$ & $3.3(1.8)$ & $4.1(2.9)$ \\
\hline $\begin{array}{l}\text { Total } 4 \text {-year nutrition curriculum hours at schools } \\
\text { using nutrition instruction in this form, average (SD) }\end{array}$ & $16.5(10.0)$ & $20.7(12.8)$ & $16.0(7.0)$ & $15.8(8.0)$ & $22.2(19.2)$ \\
\hline $\begin{array}{l}\text { Percentage of total instruction provided in that context, } \\
\text { average (SD) }\end{array}$ & $79(25)$ & $74(27)$ & $49(34)$ & $31(25)$ & $18(8)$ \\
\hline
\end{tabular}

*26/30 colleges of osteopathic medicine responded to a survey that began in 2012. Most schools that provided nutrition education did so in more than one type of course or context. SD indicates standard deviation.

the respondent's teaching assignments. Questions 10-17 inquired about required and optional obesity and weight management education, contact hours addressing obesity, and a ranking of the barriers to expanding obesity education. Participation in our survey was voluntary. The institutional review board at the University of North Carolina at Chapel Hill made the determination that this project was exempt. The survey data was collected between November 2012 and November 2014, but the survey itself asked about the nutrition education offered during the 2012/13 academic year only.

We performed calculations based on several predefined parameters. We specified zero hours of required nutrition instruction if a respondent indicated only optional nutrition education was offered at an institution. If someone gave a range of hours (e.g., 10-20 hours) in a survey response, we used the midpoint of the range in all calculations (e.g., 15 hours). In the rare case where respondents provided incomplete information, we performed basic calculations wherever possible, such as totaling the amount of nutrition education over four years. We did not predefine for respondents or place any limits on what qualifies as a "nutrition course." Educators and administrators themselves determined whether their schools provided nutrition in the various course categories.

We converted the dataset from the survey responses into a spreadsheet software program (Excel 2013, Microsoft Corp., Seattle, Washington) to perform the calculations. We calculated means and standard deviations from the survey data. This phase of our data analysis focused on the amount and type of overall nutrition education across the curriculum. The portions of the survey related to obesity teaching were not analyzed and are not reported in this publication.

\section{Results}

We received responses from 26 of the 30 targeted US colleges of osteopathic medicine and campuses (87\% response rate). Respondents from 2 (8\%) of the schools indicated that they did not require any nutrition education during the 2012/ 2013 school year. However, elective nutrition education was offered at both of these institutions. Overall, osteopathic colleges required 17.0 hours (standard deviation 12.5 hours) of required nutrition instruction. Almost all of the required nutrition instruction $(15.7 \pm 10.8$ hours) occurred during years one and two. Only 7 of the 26 responding schools

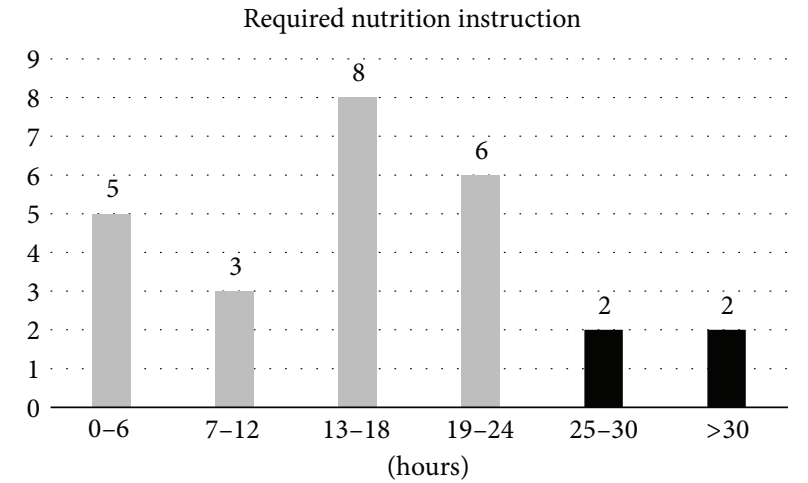

FIGURE 1: Distribution of nutrition instruction hours provided at US colleges of osteopathic medicine. 26 US colleges of osteopathic medicine responded to a survey about nutrition education during the 2012/13 academic year. This figure shows the number of schools meeting the recommended minimum requirement of 25 hours of nutrition education as indicated by the black bars compared with those providing less than the minimum as indicated by the grey bars. The number of schools falling into each category of required nutrition instruction is indicated above each bar.

required nutrition instruction during years three and four, comprising $4.1 \pm 2.9$ hours of the curriculum at those institutions.

Considering the context of nutrition instruction (e.g., dedicated nutrition instruction, biochemistry, physiology, integrated courses, or clinical nutrition practice), the greatest amount (16.3 \pm 12.3 hours) was taught together with other topics as part of integrated courses (Table 1). The four schools that reported that they required a designated nutrition course provided $14.0 \pm 8.8$ hours in that course alone, which provided $79 \%$ of their total nutrition teaching. More than half of responding colleges taught at least some nutrition in an integrated format $(16 / 26,62 \%)$. Nutrition topics were also presented in the context of biochemistry ( $6.9 \pm 5.6$ hours) and physiology ( $3.3 \pm 1.8$ hours) courses. Seven curricula taught clinical nutrition practice with an average number of 4.1 hours (standard deviation 2.9 hours).

Most of the responding schools (22/26, 85\%) did not meet the benchmark of at least 25 hours of required nutrition education across the 4-year curriculum (Figure 1). Nearly a third of them required less than half of that number of hours. 


\section{Discussion}

In light of the ongoing obesity and diabetes epidemics and morbidity and mortality related to these conditions, ensuring that physicians are ready to address the nutritional aspects of patient care seems essential. With osteopathy providing a focus on primary care and preventive medicine, it was surprising to find that most osteopathic medical schools are providing inadequate hours of nutrition instruction. The survey data show that only small percentage of responding DO schools are requiring the minimum recommended amount of nutrition education hours during their fouryear curricula. All medical schools, in particular osteopathic schools, should be offering a solid training program in something as fundamental to health maintenance and disease prevention as nutrition [6]. For medical school graduates to be competent in a field, they need to be adequately trained in terms of both hours of content delivery and practical real-world experiences. These findings that only 4 of the 26 responding osteopathic medical schools met the minimum recommended 25 hours of required nutrition education show that most of these DO students are not receiving the training they need to effectively treat their patients in maintaining health and preventing the most commonly encountered problems in the American health care system today such as obesity, diabetes, and cardiovascular disease. While we realize that this benchmark of 25 hours was a recommendation made several decades ago [27], before many medical schools moved to a more integrated or problem-based curriculum, it still can be used as a gauge for whether all students at a school are receiving the knowledge and practice skills that they need. For future DOs to be fully prepared to address the nutritional health of their patients, they need to be taught specific skills and mentored in clinical nutrition interactions. These survey results show that the amount of nutrition covered in the clinical years is very sparse and unlikely to instill the confidence and knowledge base physicians need to be skillful at effectively educating patients on nutrition issues. This is also supported in medical resident literature, where a survey found that the vast majority (86\%) of residents felt inadequately prepared to provide nutritional guidance to their patients [28], highlighting the fact that something needs to change at the medical-school level so that physicians feel more prepared to provide competent nutrition care.

\subsection{What Would It Take to Increase the Number of Nutrition} Instruction Hours? For many medical schools, the increasing content needed to fulfill basic requirements has created a very crowded curriculum [29], making for difficult decisions by curriculum administrators regarding what and how much instruction is necessary. State medical licensing exams (COMLEX for DOs and USMLE for MDs) do not put much emphasis on nutrition; therefore, some argue that until licensing exams change, curricula will not substantially change [30-32].

There are multiple curricular approaches that can be used within medical schools to increase both the quality and quantity of nutrition education during the undergraduate medical education years. The Nutrition in Medicine modules offer a convenient, economical, and unique opportunity for medical schools to increase nutrition content in their curricula. The modules are well received by students and offer medical schools both flexibility and affordability. Retaining nutrition content experts on the faculty, especially ones with real-world patient and clinical experience, and having them oversee all aspects related to nutrition and lifestyle within the curriculum to ensure all relevant topics are being addressed adequately can be very beneficial in improving the quality and quantity of nutrition education. Working with clinical faculty to include nutrition and exercise patient history-taking skills and teaching students how to assess key indicators of disease risk such as waist circumference are also valuable. Additionally, an institution's standardized patient program should include assessing and counseling overweight and obese patients for more clinically oriented experiences. For those schools using a systems-based curriculum, nutrition-related topics such as eating disorders should include a nutrition content expert as part of the behavioral medicine course. For lifestyle nutrition such as those covering issues related to pregnancy and lactation, a reproductive system course director should be sure to include pertinent nutrition topics. Collaborating with course directors for the cardiovascular and endocrine [33] systems will facilitate how and when lifestyle-related obesity, hypertension, and diabetes topics can be covered. The renal system should include information on renal diets and how these significantly impact outcomes in chronic kidney disease [33]. The musculoskeletal system can include instructional discussions on sports nutrition and physical activity needs for health maintenance and weight loss. For schools following a traditional first-year basic sciences curriculum, course directors in biochemistry and physiology should ensure adequate (but not excessive overlap) coverage is given to topics such as digestion, macro- and micronutrients, and metabolism. And finally, clinical practice sites during years three and four offer an important avenue to helping ensure medical students receive patient training in nutrition topics; however, this is often a big challenge because most osteopathic training sites are at smaller clinics, which are rightly concerned about time management and costs.

Regardless of what type of curriculum or teaching methods are in use, understanding where topics such as counseling techniques (e.g., motivational interviewing) are being taught and when students have the opportunity to practice these skills is invaluable. Surveying the curriculum to find when and where students learn about nutrition and obesity and how to talk to an obese patient to facilitate lasting behavior change is both patient-centric and practical. Teaching students to look beyond the BMI into related variables like waist circumference and family/social habits related to eating and exercise can help physicians solve problems with patients to find solutions that are more likely to work [34]. Helping today's physicians to understand health and wellness emphasizing prevention should be the goal. Adopting nutrition-related graduation competencies would be another approach to raising the likelihood of increased nutrition education during medical school. Lastly, taking advantage of organizations that are key stake-holders in 
nutrition education, such as the American Society for Nutrition (ASN), the Academy of Nutrition and Dietetics (AND), or the Association of Biochemistry Course Directors (ABCD), is important because these groups have many members who have been in the past or are currently involved with teaching nutrition or overseeing its delivery in a medical school setting.

Osteopathic schools, like their allopathic peer institutions focusing on training physicians for rural and underserved areas, often have a strong community service expectation for their student body [35]. In some cases, these are required components in the curriculum, whereas in other cases they are simply strongly encouraged and supported by administration. Exposing medical students to the reality of the socialhealth issues related to nutrition, such as childhood obesity and diabetes or hunger in their community, is highly valued by many osteopathic medical schools and their students, and anecdotal reports support their effectiveness in increasing awareness. Students who are involved in community wellness events report making the connection between what they learn in the classroom setting and what they see and do at such events. Getting a school's student body involved in community issues that have a strong focus on nutrition, obesity, and wellness is an important approach used in many osteopathic schools to increase community service and enrich the relationship between the community and the school. Some osteopathic medical schools turn to their local K-12 school system, partnering to provide nutrition education to youth while providing teaching opportunities to their student doctors. Others partner with charity or community groups (e.g., free clinics targeted at the homeless population, YMCA, local food banks, etc.) within the communities their school serves. Some schools create completely novel programs and work with the student government associations to ensure the event/program continues into the future after the students have moved on in their education. Whatever the venue, providing medical students a chance to teach what they have learned about nutrition is an effective way to enhance their learning experience and benefit the community at large.

4.2. Strengths. A great strength of our survey is its $87 \%$ response rate. Another strength is the established survey methodology, as this study builds on already-existing data which have been published previously but only included analysis of allopathic medical schools. We asked respondents to indicate the number of required nutrition hours in two different ways, allowing us to seek clarification if the numbers do not match up.

4.3. Limitations. Any survey that allows for descriptive responses requires a great effort on behalf of respondents, and researchers need to clarify and quantify the data whenever respondents do not provide ordinal numbers as part of the response. There were a few duplicate responses from some schools whereby different people submitted surveys with conflicting numbers, requiring additional one-on-one follow-up to get a determination of the actual hours offered.

\section{Conclusions}

These data highlight deficits in nutrition education at colleges of osteopathic medicine that have huge public health ramifications, especially in light of the fact that $60 \%$ of DOs practice in primary care [36]. Most schools do not dedicate enough time to prepare DOs for the daily patient encounters that require in-depth nutrition knowledge and specific practice skills. The findings reinforce the understanding that nutrition is not as well-represented in colleges of osteopathic medicine as their philosophy of holistic medicine demands. To the best of our knowledge, this is the first report of its kind looking specifically at nutrition education in osteopathic medical schools. Future studies should seek to understand the connection between undergraduate and residency-level nutrition education and knowledge, skills (proficiency), and self-confidence in nutrition counseling and related practice behaviors of osteopathic physicians.

\section{Ethical Approval}

The institutional review board of the University of North Carolina at Chapel Hill made the determination that this project has exempt status.

\section{Conflict of Interests}

The authors declare that there is no conflict of interests regarding the publication of this paper.

\section{Acknowledgments}

The authors thank all the colleges of osteopathic medicine faculty and administrative members who completed surveys and provided many helpful comments. The Nutrition in Medicine project was supported in part by Grants R25CA65474 and R25CA134285 from the National Cancer Institute, by Grant DK56350 for the UNC Clinical Nutrition Research Unit, and by funds from the UNC Nutrition Research Institute.

\section{References}

[1] Centers for Disease Control, Leading Causes of Death, CDC, 2014, http://www.cdc.gov/nchs/fastats/leading-causes-of-death .htm.

[2] R. F. Kushner, L. van Horn, C. L. Rock et al., "Nutrition education in medical school: a time of opportunity," The American Journal of Clinical Nutrition, vol. 99, no. 5, supplement, pp. 1167S-1173S, 2014.

[3] B. Wansink, "Position of the American Dietetic Association: food and nutrition misinformation," Journal of the American Dietetic Association, vol. 106, no. 4, pp. 601-607, 2006.

[4] K. M. Kolasa and K. Rickett, "Barriers to providing nutrition counseling cited by physicians: a survey of primary care practitioners," Nutrition in Clinical Practice, vol. 25, no. 5, pp. 502-509, 2010.

[5] B. S. Rosen, P. J. Maddox, and N. Ray, "A position paper on how cost and quality reforms are changing healthcare in America: 
focus on nutrition," Journal of Parenteral and Enteral Nutrition, vol. 37, no. 6, pp. 796-801, 2013.

[6] P. M. Kris-Etherton, S. R. Akabas, C. W. Bales et al., "The need to advance nutrition education in the training of health care professionals and recommended research to evaluate implementation and effectiveness," The American Journal of Clinical Nutrition, vol. 99, supplement 5, pp. 1153S-1166S, 2014.

[7] J. E. Harris, V. Hamaday, and E. Mochan, "Osteopathic family physicians' attitudes, knowledge, and self-reported practices regarding obesity," The Journal of the American Osteopathic Association, vol. 99, no. 7, pp. 358-365, 1999.

[8] R. A. Dimaria-Ghalili, M. Edwards, G. Friedman et al., "Capacity building in nutrition science: revisiting the curricula for medical professionals," Annals of the New York Academy of Sciences, vol. 1306, no. 1, pp. 21-40, 2013.

[9] C. M. Lenders, D. D. Deen, B. Bistrian et al., "Residency and specialties training in nutrition: a call for action," The American Journal of Clinical Nutrition, vol. 99, no. 5, supplement, pp. 1174S-1183S, 2014.

[10] K. M. Adams, M. Kohlmeier, and S. H. Zeisel, "Nutrition education in U.S. medical schools: latest update of a national survey," Academic Medicine, vol. 85, no. 9, pp. 1537-1542, 2010.

[11] D. S. McLaren, "Nutrition in medical schools: a case of mistaken identity," American Journal of Clinical Nutrition, vol. 59, no. 5, pp. 960-963, 1994.

[12] M. Chung, V. J. van Buul, E. Wilms, N. Nellessen, and F. J. P. H. Brouns, "Nutrition education in European medical schools: results of an international survey," European Journal of Clinical Nutrition, vol. 68, no. 7, pp. 844-846, 2014.

[13] American Association of Colleges of Osteopathic Medicine (AACOM), "Osteopathic Medical Profession Report. 2012," http://www.osteopathic.org/inside-aoa/about/aoa-annual-statistics/Documents/2012-OMP-report.pdf.

[14] American Osteopathic Association (AOA), DOs Around the World, 2015, http://www.osteopathic.org/osteopathic-health/ about-dos/dos-around-the-world/Pages/default.aspx.

[15] D. J. Colegrove and B. E. Whitacre, "Interest in rural medicine among osteopathic residents and medical students," Rural and Remote Health, vol. 9, no. 3, p. 1192, 2009.

[16] M. Cummings and K. J. Dobbs, "The irony of osteopathic medicine and primary care," Academic Medicine, vol. 80, no. 7, pp. 702-705, 2005.

[17] A. S. Peters, N. Clark-Chiarelli, and S. D. Block, "Comparison of osteopathic and allopathic medical schools' support for primary care," Journal of General Internal Medicine, vol. 14, no. 12, pp. 730-739, 1999.

[18] American Association of Colleges of Osteopathic Medicine (AACOM), "Overview of osteopathic medical education/ accreditation/the four-year curriculum," in Osteopathic Medicine Information Book, American Association of Colleges of Osteopathic Medicine, 2015, https:/www.aacom.org/docs/ default-source/cib/2015cib_p10-11.pdf?sfvrsn=2.

[19] American Osteopathic Association, Tenets of Osteopathic Medicine, 2014, http://www.osteopathic.org/inside-aoa/about/leadership/Pages/tenets-of-osteopathic-medicine.aspx.

[20] R. Hopkins, D. Pratt, J. L. Bowen, and G. Regehr, "Integrating basic science without integrating basic scientists: reconsidering the place of individual teachers in curriculum reform," Academic Medicine, vol. 90, no. 2, pp. 149-153, 2015.

[21] B. Ross-Lee, D. L. Wood, D. D. Mann, R. P. Portanova, L. E. Kiss, and M. A. Weiser, "An osteopathic prescription for medical education reform. Part 1. Curriculum and infrastructure," The Journal of the American Osteopathic Association, vol. 97, no. 7, pp. 403-408, 1997.

[22] S. C. Shannon, "Reevaluating osteopathic medical education for the 21st century and beyond," Journal of the American Osteopathic Association, vol. 114, no. 4, pp. 228-230, 2014.

[23] S. C. Shannon and H. S. Teitelbaum, "The status and future of osteopathic medical education in the United States," Academic Medicine, vol. 84, no. 6, pp. 707-711, 2009.

[24] K. M. Adams, W. S. Butsch, and M. Kohlmeier, "The state of nutrition education at US medical schools," Journal of Biomedical Education. In press.

[25] K. M. Adams, M. Kohlmeier, M. Powell, and S. H. Zeisel, "Nutrition in medicine: nutrition education for medical students and residents," Nutrition in Clinical Practice, vol. 25, no. 5, pp. 471480, 2010.

[26] K. C. Lindell, K. M. Adams, M. Kohlmeier, and S. H. Zeisel, “The evolution of nutrition in medicine, a computer-assisted nutrition curriculum," The American Journal of Clinical Nutrition, vol. 83, no. 4, pp. 956S-962S, 2006.

[27] Committee on Nutrition in Medical Education Food and Nutrition Board, Commission on Life Sciences, and National Research Council, Nutrition Education in U.S. Medical Schools, The National Academies Press, Washington, DC, USA, 1985.

[28] M. L. Vetter, S. J. Herring, M. Sood, N. R. Shah, and A. L. Kalet, "What do resident physicians know about nutrition? An evaluation of attitudes, self-perceived proficiency and knowledge," Journal of the American College of Nutrition, vol. 27, no. 2, pp. 287-298, 2008.

[29] P. Gallagher, N. Wilson, and R. Jaine, "The efficient use of movies in a crowded curriculum," Clinical Teacher, vol. 11, no. 2, pp. 88-93, 2014.

[30] C. Lo, "Integrating nutrition as a theme throughout the medical school curriculum," The American Journal of Clinical Nutrition, vol. 72, no. 3, supplement, pp. 882S-889S, 2000.

[31] J. Haddad, "Nutrition needs to be taught in medical school," KevinMD.com Blog, 2011, http://www.kevinmd.com/blog/2011/ 12/nutrition-taught-medical-school.html.

[32] N. P. Morris, "The neglect of nutrition in medical education: a firsthand look," JAMA Internal Medicine, vol. 174, no. 6, pp. 841842, 2014.

[33] M. M. Estrella, B. G. Jaar, K. L. Cavanaugh et al., "Perceptions and use of the national kidney foundation KDOQI guidelines: a survey of U.S. renal healthcare providers," BMC Nephrology, vol. 14, no. 1, article 230, 2013.

[34] J. Stubbs, S. Whybrow, P. Teixeira et al., "Problems in identifying predictors and correlates of weight loss and maintenance: implications for weight control therapies based on behaviour change," Obesity Reviews, vol. 12, no. 9, pp. 688-708, 2011.

[35] A. Vohra and Z. Meyler, "The Disaster Reserve Partner Group at NYCOM," Journal of the American Osteopathic Association, vol. 103, no. 11, pp. 505-506, 2003.

[36] American Osteopathic Association, What is a DO?, 2014, http:// www.osteopathic.org/osteopathic-health/about-dos/what-is-ado/Pages/default.aspx. 

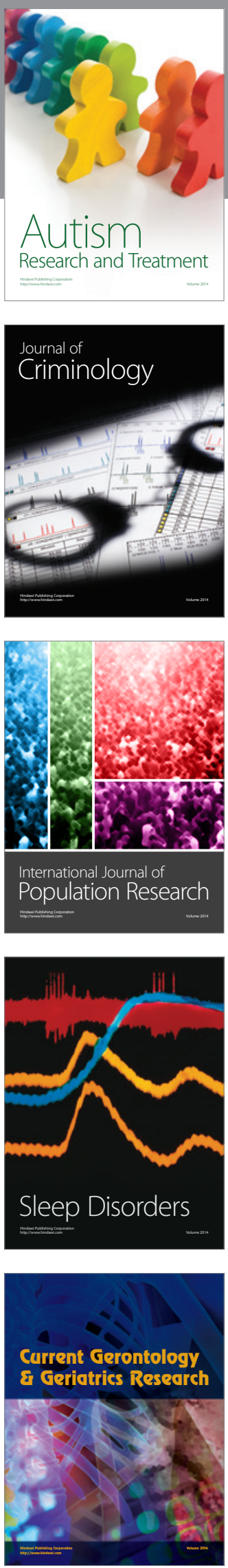
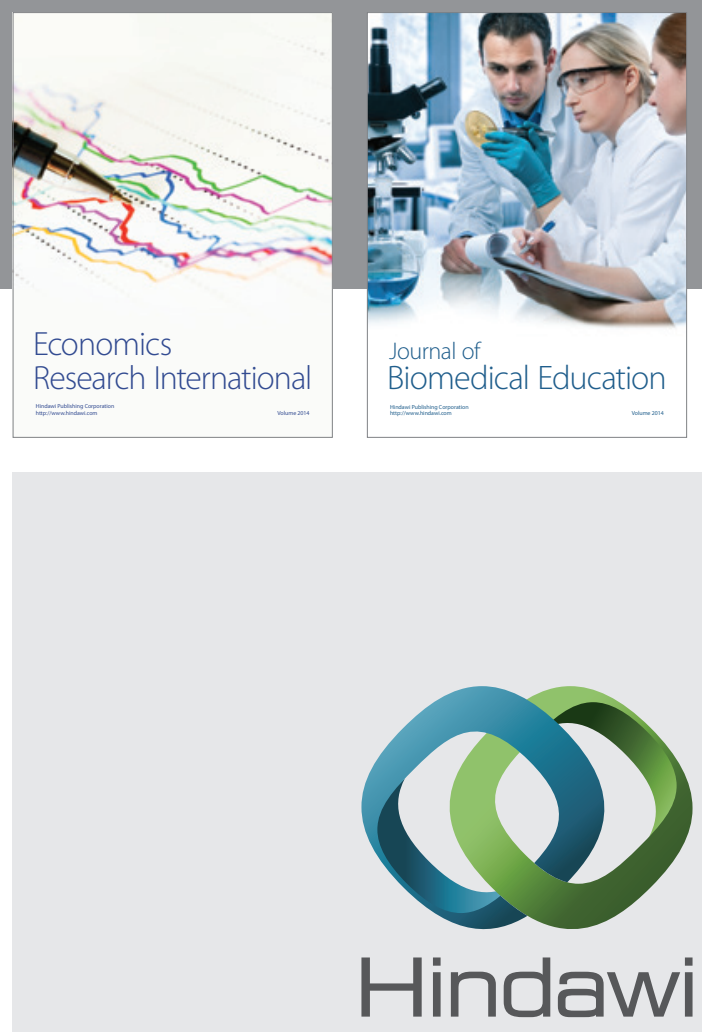

Submit your manuscripts at

http://www.hindawi.com
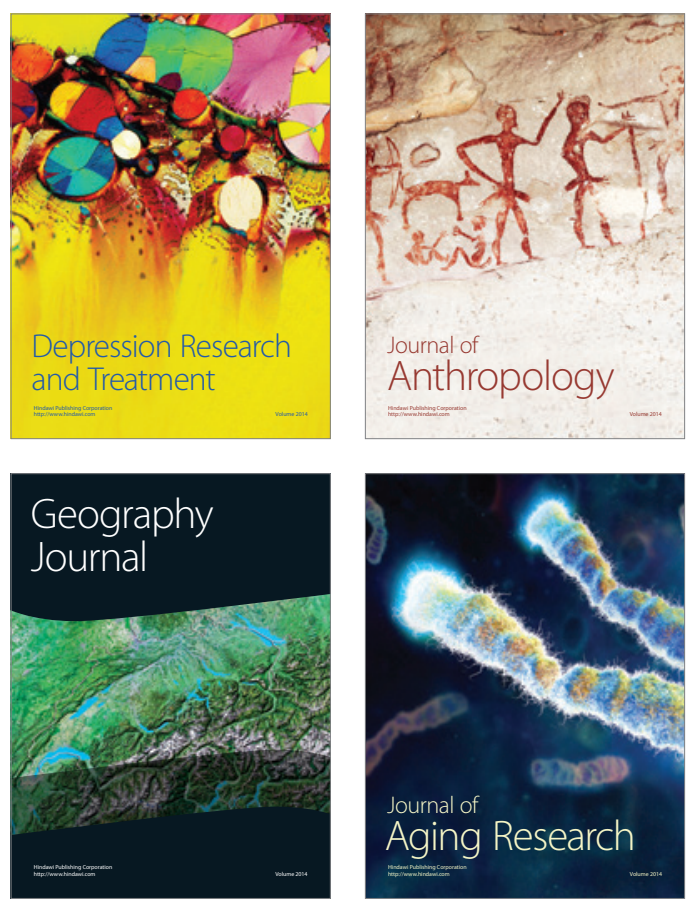
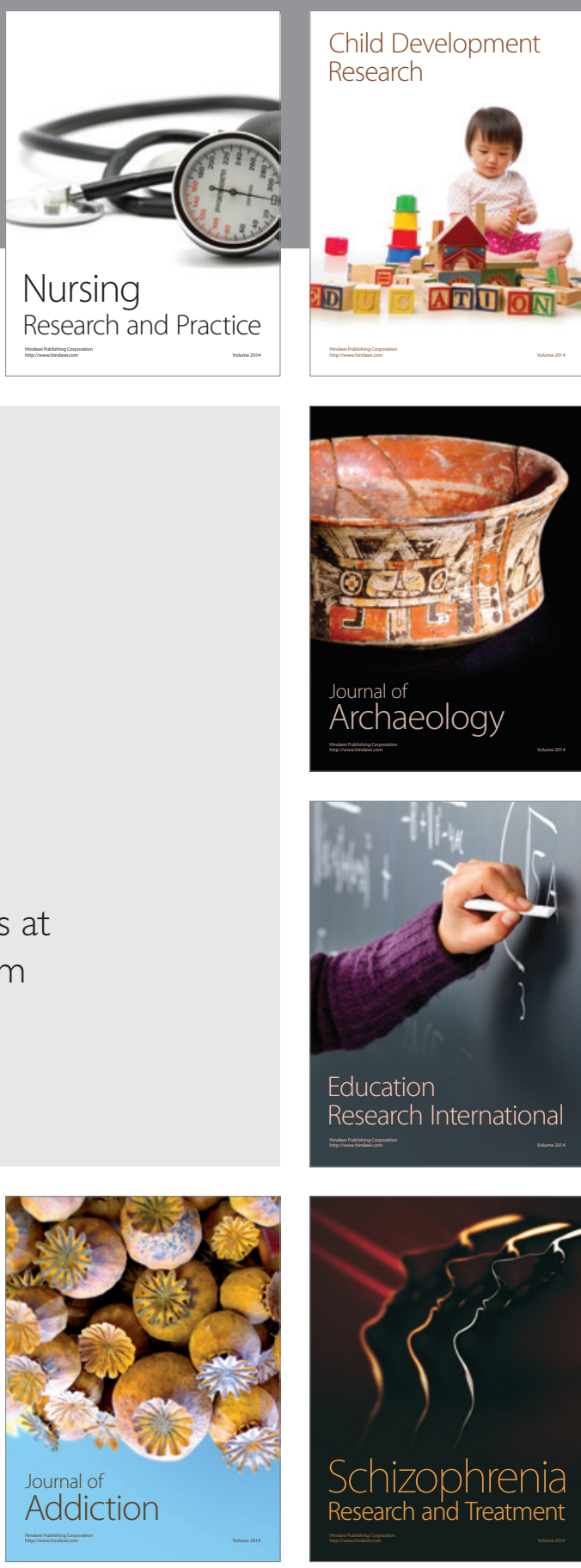

(D)
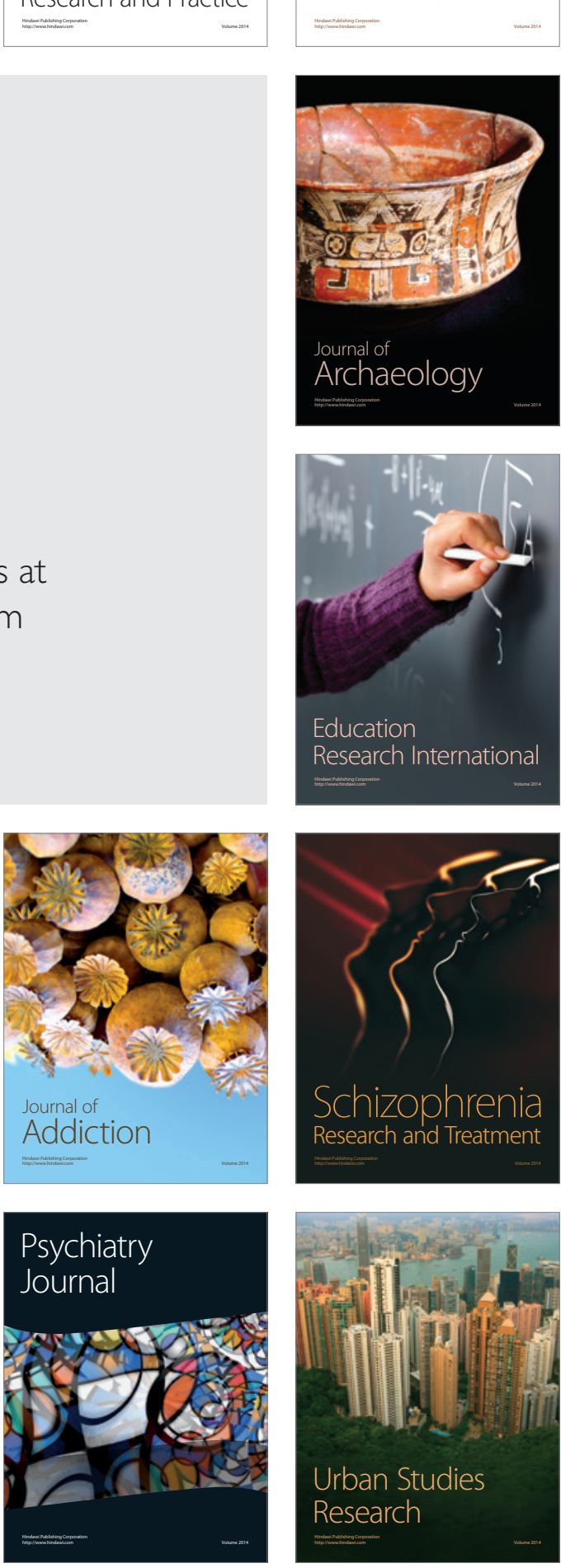